\title{
Cerebral hypoperfusion as assessed by transcranial duplex in posterior reversible encephalopathy syndrome
}

\author{
Miguel Alberte-Woodward, Olga García-Pazos, Mónica Guijarro-del Amo
}

Servicio de Neurología, Hospital Universitario Lucus Augusti, Lugo, Spain

To the Editor,

Posterior reversible encephalopathy syndrome (PRES) is an entity mainly affecting the posterior cerebral circulation usually in the context of hypertension. Clinical manifestations may include headache, disturbance of consciousness, seizures and visual impairment. The condition typically develops in relation to hypertensive encephalopathy or eclampsia, the commonly held view being that a failure of cerebral autoregulatory mechanisms is followed by hyperperfusion, vasodilatation, fluid extravasation and brain oedema [1]. Nevertheless, a constellation of other causes including the use of immunosuppressant drugs has been associated with PRES, up to $15-20 \%$ of patients are normotensive or hypotensive and a dysfunction of endothelial cells has also been proposed as a causative mechanism [1]. Cerebral hypoperfusion has seldom been documented, such as in a paper reporting a reduction in cerebral blood flow values as assessed by computed tomography (CT) perfusion in 2 out of 4 patients with PRES [2].

We report the case of a 47-year-old male with an unremarkable past medical history presenting at the Emergency Department because of headache and visual difficulties arising in the previous hours. Upon admission his blood pressure was $234 / 138 \mathrm{~mm} \mathrm{Hg}$, he was somnolent and had difficulty nominating and a right homonymous hemianopia by confrontation. Non-contrast CT was normal and a bedside transcranial duplex (TCD) ultrasound was performed. Whilst the pulse-wave spectrums in both

Received 14.10.2020 Accepted 13.12.2020

Med Ultrason

2021, Vol. 23, No 1, 114-115, DOI: 10.11152/mu-2935,

Corresponding author: Miguel Alberte-Woodward

Servicio de Neurología, Hospital Universitario

Lucus Augusti. 27003 Lugo, Spain

Rúa Dr. Ulises Romero s/n. 27003 Lugo, Spain

Phone: +34 982296000

Fax: +34 982295544

E-mail: malbertewoodward@yahoo.es

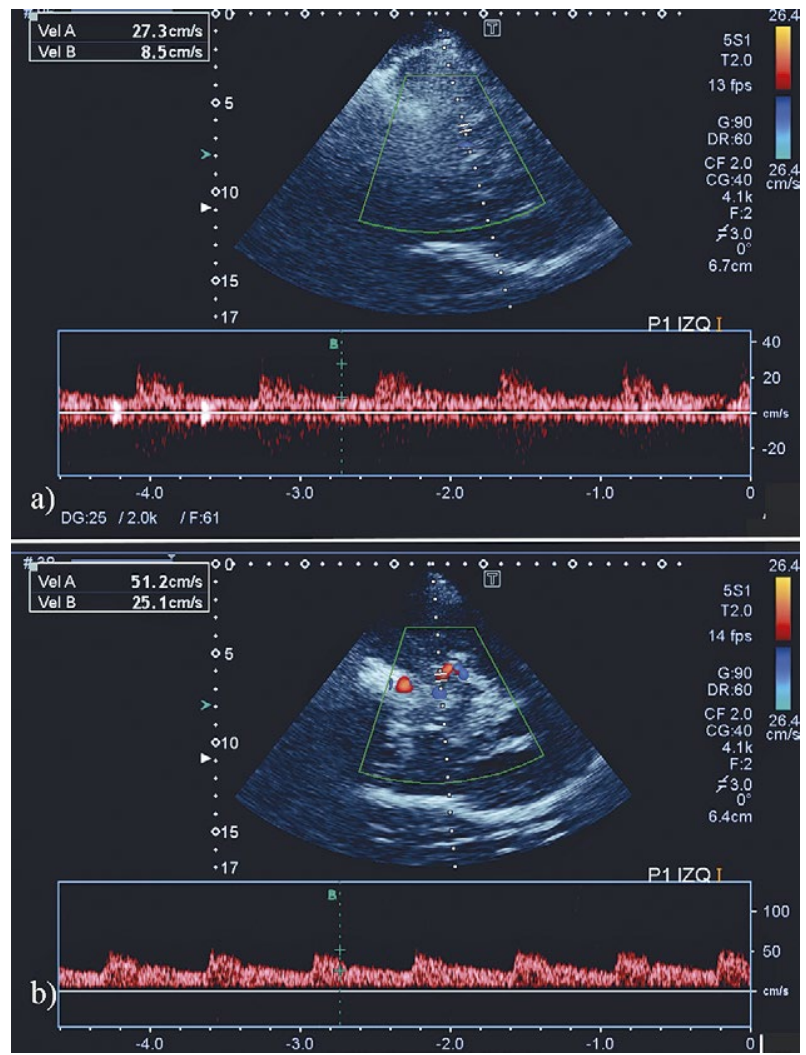

Fig 1. a) Baseline duplex scan of P1 segment of left posterior cerebral artery; b) follow-up scan showing normalisation of the flow pattern.

middle cerebral arteries and right posterior cerebral artery (PCA) were normal, left PCA - corresponding to the symptomatic territory - showed a marked reduction in the flow in its proximal segments $(25.3 / 15.2 \mathrm{~cm} / \mathrm{s}$, fig $1 \mathrm{a}$, as compared to reference velocities of $60 \pm 14 / 28 \pm 9 \mathrm{~cm} / \mathrm{s}$ [3]).

He was diagnosed with PRES and hypertensive emergency and parenteral urapidil was initiated. Brain magnetic resonance imaging (MRI) was performed 24 hours after admission, and was unremarkable. Blood pressure 
was eventually controlled with a combination of five drugs, three of which he was successfully weaned off. By means of a renal MR angiography he was diagnosed with a stenosis of the superior artery of the right kidney, likely explaining the severe hypertension.

Forty-eight hours after admission he was neurologically asymptomatic, and a follow-up TCD obtained 18 days after admission showed a resolution of the hypoperfusion in the left PCA, with velocities of $48.4 / 22.1 \mathrm{~cm} / \mathrm{s}$ (fig 1b).

This case further supports the notion that some PRES cases may present with cerebral hypoperfusion. To the best of our knowledge, this is the first report of it being documented by TCD ultrasonography.

\section{References}

1. Shankar J, Banfield J. Posterior Reversible Encephalopathy Syndrome: A Review. Can Assoc Radiol J 2017;68:147-153.

2. Vanacker P, Matias G, Hagmann P, Michel P. Cerebral Hypoperfusion in Posterior Reversible Encephalopathy Syndrome is Different from Transient Ischemic Attack on CT Perfusion. J Neuroimaging 2015;25:643-646.

3. Valdueza JM, Schreiber SJ, Roehl JE, Klingebiel R. (eds). Neurosonology and Neuroimaging of Stroke. Thieme, 2008.

\title{
In different shoulder pathologies, three different treatments can be performed with one needle under ultrasound guidance: technical advice
}

\author{
Fatih Bagcier ${ }^{1}$, Ozan Volkan Yurdakul $^{2}$, Erkan Özduran ${ }^{3}$
}

${ }^{1}$ Department of Physical Medicine and Rehabilitation, Çam ve Sakura City Hospital, ${ }^{2}$ Department of Physical Medicine and Rehabilitation, Bezmialem University Faculty of Medicine, ${ }^{3}$ Department of Physical Medicine and Rehabilitation, Haseki Training and Research Hospital, Istanbul Turkey

\section{To the Editor,}

Hemiplegic shoulder pain and chronic shoulder pain are conditions that affects the rehabilitation process negatively and extends the duration of hospitalization. Myofascial trigger points (MTrPs) in shoulder muscles are related to hemiplegic and chronic shoulder pain. A suprascapular nerve block with ultrasound (US) guidance is used for treating the hemiplegic shoulder pain $[1,2]$. In addition to this procedure, dry needling (DN) to MTrPs can be performed simultaneously. Fortunately, MTrPs in the upper trapezius and supraspinatus muscles can

Received 18.10.2020 Accepted 13.12.2020

Med Ultrason

2021, Vol. 23, No 1, 115-116, DOI: 10.11152/mu-2885,

Corresponding author: Dr. Fatih Bagcier

Department of Physical Medicine and

Rehabilitation,

Çam ve Sakura City Hospital, İstanbul

ORCID number: 0000-0002-6103-7873

Phone: +90 2123447087

Fax: +90 2122361014

E-mail: bagcier_42@hotmail.com be treated by the same needle at the course of the nerve block procedure. Another advantage of this method is that a twitch response can be seen clearly via US during the process.

For the intervention, the patient must be in a sitting position and a $23 \mathrm{G}(50 \mathrm{~mm}-80 \mathrm{~mm})$ size spinal needle is required. The first procedure is the treatment of MTrP of the upper trapezius and supraspinatus muscles. The penetration angle of the needle into the body should be about $30-45^{\circ}$ (fig 1a). After the needle penetrates these muscles, navigation should be done until a twitch response is obtained. Here, it is possible to end the first procedure either with dry needling or with a local anaesthesia injection. The second procedure is the suprascapular nerve block. The needle penetration angle for this process is $60-75^{\circ}$ (fig $1 \mathrm{~b}$ ).

The aim of this paper is not to avoid such methods but to take advantage of treating different muscles with a single injection if it is possible. In this sense, an individual with thoracic MTrPs who was treated with lidocaine injection to five adjacent anatomical structures with a single injection, was presented [3]. Thus, a comfortable 


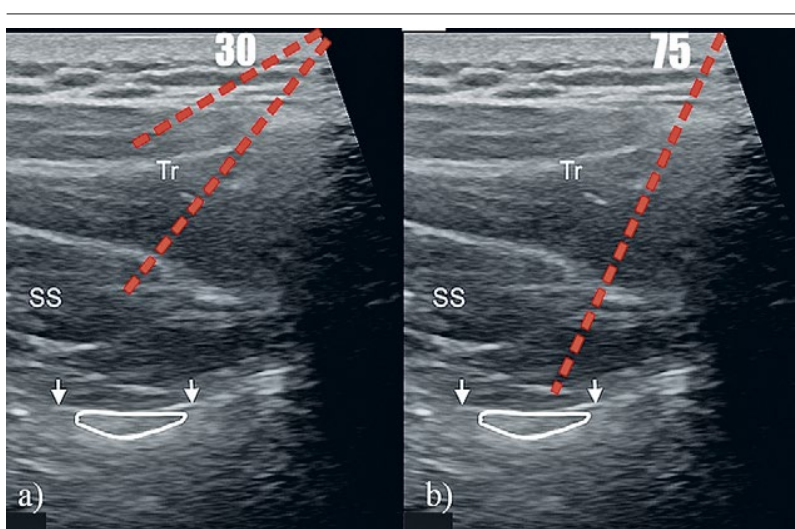

Fig 1. a) Dry needling treatment of upper trapezius muscle ( $\mathrm{Tr})$ and supraspinatus (SS) muscle; b) Suprascapular nerve bloc

treatment can be offered to patients with needle phobia, and complications of invasive procedures, especially in- fections, can be reduced. Every needle inserted into the body increases the risk of complications. Saving of time and medical supplies may be another advantage.

\section{References}

1. Arias-Buría JL, Valero-Alcaide R, Cleland JA, et al. Inclusion of trigger point dry needling in a multimodal physical therapy program for postoperative shoulder pain: a randomized clinical trial. J Manipulative Physiol Ther 2015;38:179-187.

2. Shanahan EM, Smith MD, Wetherall M, et al. Suprascapular nerve block in chronic shoulder pain: are the radiologists better? Ann Rheum Dis 2004;63:1035-1040.

3. Tang TY, Shyu SG, Kao BC, Wu CH. Ultrasound-Guided 5-in-1 Injection: Trigger Point Injections and Nerve Hydrodissections for Nonspecific Upper Back Pain. Am J Phys Med Rehabil 2019;98:e55-e56.

\title{
Ultrasonographic imaging of supinator injury and hematoma after a fall
}

\author{
Yi-Hsiang Chiu, Tyng-Guey Wang
}

Department of Physical Medicine and Rehabilitation, National Taiwan University Hospital, Taipei, Taiwan

\section{To the Editor,}

A 45-year-old woman had left lateral elbow pain and numbness after falling with an outstretched hand on her way to the fitting room before swimming. Acute onset of swelling with bruise was noticed over the lateral elbow. Range of motion of elbow remained intact initially. However, the pain exacerbated when she tried to extend or rotate her elbow after swimming. She visited the emergency department right away and the X-ray revealed no

Received 30.10.2020 Accepted 13.12.2020

Med Ultrason

2021, Vol. 23, No 1, 116-117, DOI: 10.11152/mu-2910,

Corresponding author: Dr. Tyng-Guey Wang

Department of Physical Medicine

and Rehabilitation,

National Taiwan University Hospital

7 Zhongshan South Road,

Zhongzheng District,

Taipei City 100, Taiwan

Phone: 886-2-23123456-67587

E-mail address: tgw@ntu.edu.tw obvious bony fracture. Two days after the fall, the range of motion of elbow had gradually improved. Nonetheless, lateral elbow pain with occasional tingling sensation still persisted in the following days.

She visited the outpatient clinic two weeks after the fall. Physical examination revealed left radial head tenderness. Muscle power of supination was 4 at left side, and 5 at right side. Left forearm supination limitation was noticed, with 10 degrees less than the right side. Ultrasonography showed a $6.9 \times 9.1 \mathrm{~mm}$ hyperechoic to isoechoic mass in the left supinator muscle, which was compatible with a hematoma (fig 1, white arrow). The ligaments around the elbow joint and distal biceps tendon remained intact. No bony irregularity was noticed at the humerus or radius. The deep branch of the radial nerve (fig 1, red arrow) was slightly compressed by the hematoma. However, she denied weakness of wrist extension.

Supinator is the muscle responsible for forearm supination. It contains two heads, comprising the superficial and deep head. Previous reports had not shown isolated hematoma in the supinator after the fall. We 


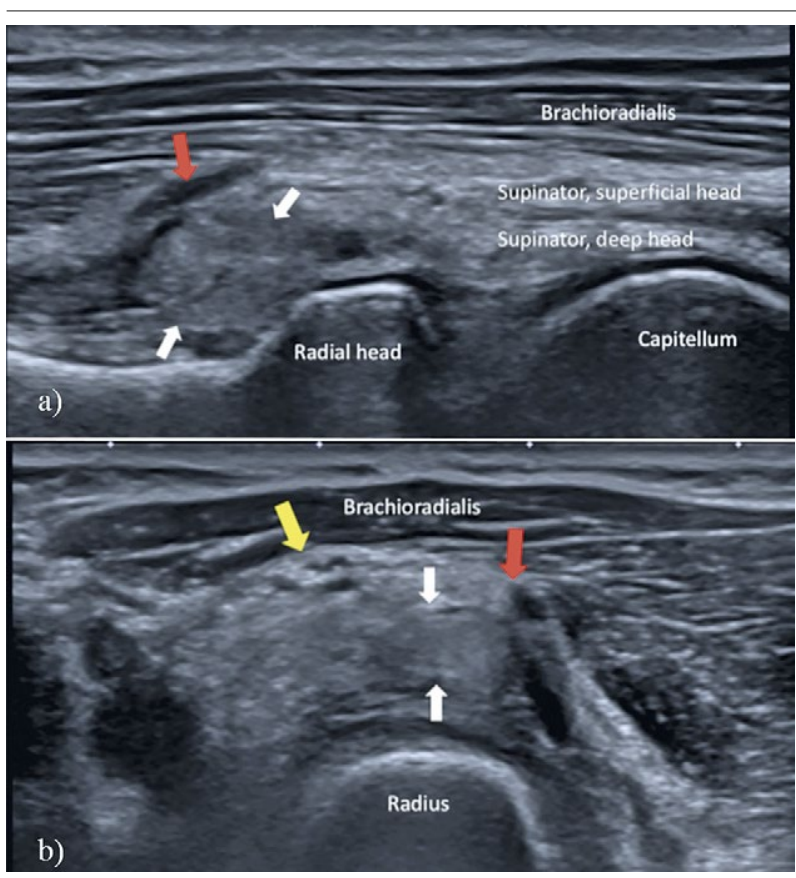

Fig 1. Ultrasonography imaging of the left supinator injury and the hematoma in a sagittal view (a) and coronal view (b). White arrow: hematoma; red arrow: deep branch of radial nerve; yellow arrow: superficial branch of radial nerve.

presume that the patient had isolated a supinator injury due to a powerful torque summation on the supinator
[1]. The muscle exhibited eccentric contraction to confront with the torque, and eventually led to myofibrillar damage [2]. Forceful contraction of the supinator muscle also disrupted the branches of the radial artery beneath the supinator, and led to the formation of intramuscular hematoma.

Tendons, ligaments and nerves surrounding the supinator deserve close attention after muscle injury. A case report showed that a distal biceps tendon might be ruptured concomitantly with a supinator muscle tear [3]. The deep branch of the radial nerve, also known as the deep radial motor branch, /first supplies the supinator and then pierces through the supinator to supply the extensor of the wrist. It might be easily entrapped after a muscle injury. Therefore, the wrist extension should be carefully checked after a supinator injury.

\section{Reference}

1. Black CD, Elder CP, Gorgey A, Dudley GA. High specific torque is related to lengthening contraction-induced skeletal muscle injury. J Appl Physiol 2008;104:639-647.

2. Lieber RL, Fridén J. Mechanisms of muscle injury after eccentric contraction. J Sci Med Sport 1999;2:253-265.

3. Nayyar S, Quirno M, Hasan S, Rybak L, Meislin RJ. Rupture of the Distal Biceps Tendon Combined with a Supinator Muscle Tear in a 51-Year-Old Woman: A Case Report. Case Rep Radiol 2011;2011:515912.

\title{
Three-dimensional echocardiography in rapid differentiation of the left ventricular mass - a case of left ventricular myxoma
}

\author{
Damir Fabijanić1, Duško Kardum², Bruno Lukšić3 ${ }^{3}$, Vedran Carević1
}

${ }^{1}$ Department of Cardiology, University Hospital of Split and University of Split School of Medicine, Split, ${ }^{2}$ Department of Internal Medicine, Clinical Hospital Dubrava Zagreb and University of J.J. Strossmayer Osijek, ${ }^{3}$ Department of Surgery, University Hospital of Split and University of Split School of Medicine, Split, Croatia

Received 28.12.2020 Accepted 03.01.2021

Med Ultrason

2021, Vol. 23, No 1, 117-118, DOI: 10.11152/mu-3002,

Corresponding author: Prof. Damir Fabijanić

Department of Cardiology,

Split University Hospital of Split,

Šoltanska 1,

Split, Croatia

Phone: +38521556272

Fax: +38521556031

E-mail: damirfabijanic62@gmail.com

\section{To the Editor,}

A 54-year-old obese man (body mass index $35.5 \mathrm{~kg}$ / $\mathrm{m}^{2}$ ), in sinus rhythm, without previous history of cardiovascular diseases, was referred to our department for evaluation of a left ventricular (LV) mass incidentally detected during outpatient 2D transthoracic echocardiography (2DTTE). The mass was round, clearly delineated, slightly mobile homogeneous, with a focal calcifi- 


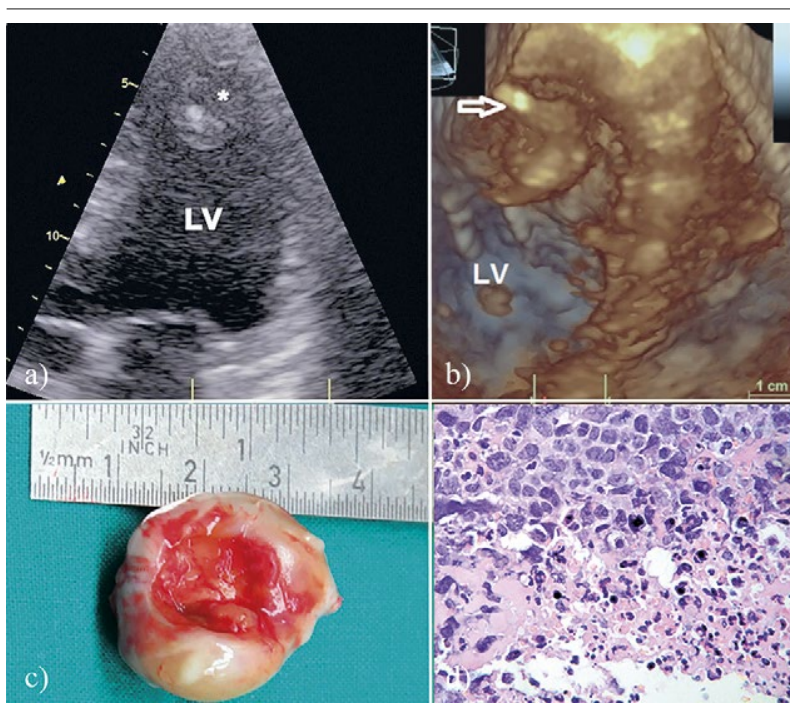

Fig 1. Echocardiographic and morphological appearance of the left ventricular (LV) mass: 2D transthoracic echocardiography showed a slightly mobile round mass in the LV apex (asterisk), suspected for a thrombus (a); 3D transthoracic echocardiography allowed a detailed morphological analysis of the mass with clear visualization of a stalk (white arrow; b); the surgically removed mass (c) was histopathologically confirmed as a myxoma (d).

cation, measuring $27 \times 22 \mathrm{~mm}$ and was located in the apex of the normally sized LV with preserved ejection fraction and no regional wall motion abnormalities (fig 1a). Due to suspicion of thrombus, outpatient treatment with a low-molecular-weight-heparin was initiated. Threedimensional transthoracic echocardiography (3DTTE) performed immediately after admission allowed a more detailed morphological analysis of the mass and surrounding cardiac structures, clearly demonstrating a stalk attached to the apicolateral LV segment (fig 1b), as one of the pathognomonic signs of cardiac myxoma. Chest radiographs, electrocardiogram, blood tests and coronary angiography revealed normal findings. Histopathological examination of the surgically removed mass confirmed a preoperative diagnosis (fig $1 \mathrm{c}$ and $1 \mathrm{~d}$ ).

Localization of myxoma in LV is found in less than $2 \%$ of all cases of this benign cardiac tumor [1]. This rare and unexpected localization, especially in case of sub-optimal 2DTTE visualization (e.g. due to body habitus or possible concomitant lung pathology), may cause difficulties in their differentiation from other types of intracardiac masses [2]. A comprehensive echocardiographic examination using 3DTTE techniques provides a detailed and precise spatial visualization of intracardiac structures, thus enabling accurate assessment of mass morphology, size and attachment to the surrounding cardiac structures allowing a rapid, accurate and precise diagnosis avoiding the need for more expensive and less accessible cardiac imaging techniques (such as computed tomography or magnetic resonance imaging).

\section{References}

1. Reynen K. Cardiac myxomas. N Engl J Med 1995;333:16101617.

2. Kirmani BH, Binukrishnan S, Gosney JR, Pullan DM. Left ventricular apical masses: distinguishing benign tumors from apical thrombi. Eur J Cardiothorac Surg 2016;49: 701-703

\section{Dynamic ultrasonography for assessing the nerve-fasciae relationship in entrapment syndromes}

\section{Carmelo Pirri ${ }^{1}$, Carla Stecco ${ }^{1}$, Caterina Fede ${ }^{1}$, Raffaele De Caro ${ }^{1}$, Levent Özçakar ${ }^{2}$}

${ }^{1}$ University of Padova, Department of Neurosciences, Institute of Human Anatomy, Padova, Italy, ${ }^{2}$ Hacettepe University Medical School, Department of Physical and Rehabilitation Medicine

Received 07.12.2020 Accepted 05.01.2021

Med Ultrason

2021, Vol. 23, No 1, 118-119, DOI: 10.11152/mu-2982,

Corresponding author: Carmelo Pirri

Department of Neurosciences,

Institute of Human Anatomy,

Via Gabelli 65, 35121, Padova, Italy

E-mail: carmelop87@hotmail.it

\section{To the Editor,}

A 26-year-old male bodybuilder had initially been examined for a pre-season routine evaluation two years ago when physical and ultrasound (US) examinations for upper limb nerves had been normal. On a control visit (40 days ago), they had been again unremarkable; however, 
he had complained of a slight stiffness in the movements of his left upper limb where dynamic US examination had shown only mild changes in the median nerve. Recently, he was seen for a two-week history of left wrist pain and stiffness together with paresthesia in all fingers. Physical examination was unremarkable except for reduced grip strength without any atrophy.

Comparative wrist and forearm US imaging [1] performed using a high frequency linear probe (6-15 $\mathrm{MHz}$, Sonosite Edge II, FUJIFILM) - was normal. To further evaluate the site of maximum pain (indicated by the patient), sono-palpation (using axial imaging) was performed over a region of $2 \mathrm{~cm}$ proximal to the wrist and at mid-forearm $(10 \mathrm{~cm}$ distal to the elbow). Initially, static imaging was carried out with the patient in seated position, his elbows in flexion, forearms in supination and shoulders in neutral position. Proximally, the median nerve was scanned as it left the ulnar artery and traveled within the fascial plane between flexor digitorum superficialis (FDS) and flexor digitorum profundus (FDP) muscles, and surrounded by fat. Distally, the nerve was scanned at the proximal carpal tunnel (between the scaphoid and the pisiform tubercle). At both locations, the nerve appeared to be normal.

Further dynamic scanning was performed during active wrist/finger flexions and the median nerve movement pattern was clearly different from the contralateral asymptomatic side (Videos 1-4) as well as from the previous videos of his former control visit 40 days ago (Videos 5-8). In particular; while the right median nerve displayed a 'diving pattern' inside the fascial plane between FDS and FDP muscles with an immediate subsequent return to its neutral position, a similar harmonious movement of the median nerve was absent on the left side. This 'rigid' movement pattern was also observed at the wrist level. Manual therapy (Fascial Manipula$\operatorname{tion}^{\circledR}$ ) and exercises of stretching were prescribed. After four weeks, the patient reported significant pain relief, no stiffness in the upper limb and recovery of grip strength.

By presenting this case, we are drawing attention to the role of simple dynamic US imaging even in cases with mild differences whereby the discussion from the side of fasciae might be contributory [2]. Recent research highlighted that median nerve undergoes tractions, mostly transversally, by paraneural sheath which is considered a specialized part of the deep fascia playing a role in myofascial force transmission [3]. Moreover, the fascial layers envelop it and they are somatic structures richly innervated by both $\mathrm{A} \delta$ and $\mathrm{C}$ free nerve endings [4].

In conclusion, we highlight the paramount/convenient role of dynamic US examination in the assessment and monitoring of this intriguing relationship - especially in patients with ambiguous symptomatology.

\section{References}

1. Wu CH, Chang KV, Özçakar L, et al. Sonographic tracking of the upper limb peripheral nerves: a pictorial essay and video demonstration. Am J Phys Med Rehabil 2015;94:740-747.

2. Stecco A, Pirri C, Stecco C. Fascial entrapment neuropathy. Clin Anat 2019;32:883-890.

3. Stecco C, Giordani F, Fan C, et al. Role of Fasciae around the Median Nerve in Pathogenesis of Carpal Tunnel Syndrome: Microscopic and Ultrasound Study. J Anat 2020;236:660-667.

4. Pirri C, Stecco C, De Caro R, Foti C, Özçakar L. Radiating Upper Limb Pain Due to a Large Subcutaneous Lipoma: Fascial Sono-Palpation. Pain Med 2020;21:3721-3723. 


\title{
Plantar vein thrombosis: an unexpected cause of posttraumatic foot pain explained with ultrasound
}

\author{
Kamal Mezian', Laura Hrehová2 ${ }^{2}$ Karolína Sobotová ${ }^{3}$
}

${ }^{1}$ Department of Rehabilitation Medicine, First Faculty of Medicine, Charles University and General University Hospital in Prague, ${ }^{2}$ Institute of General Practice, First Faculty of Medicine, Charles University, ${ }^{3}$ Department of Rehabilitation and Sports Medicine, Second Faculty of Medicine, Charles University and University Hospital Motol, Prague, Czech Republic

\section{To the Editor,}

A 49-year-old man presented with a one-month history of pain in the sole of his right foot, resulting in the inability to ambulate without crutches and pain-related sleep disturbances. Prior to this, he had experienced sudden pain in his sole during the take-off when playing football and tennis. Initially, he was examined in the emergency department, where plain radiographs showed no abnormalities. The patient received a diagnosis of a foot sprain, treated with an ankle brace and walking with crutches.

He denied any medical history. He worked as an office worker and his regular physical activity comprised uphill running.

His current physical examination revealed a livid skin color, swelling of the dorsal aspect of his foot, hematoma and local tenderness on the foot's plantar aspect (with a maximum at the level of the metatarsal heads and center of the sole). The patient reported severe pain when resisted flexion of toes was performed. There was no restriction in the ankle motions.

Ultrasound imaging (3-16 $\mathrm{MHz}$ linear array probe; UGEO HM70A, Samsung, Seoul) was performed. and a hypoechoic non-compressible tubular-like structure coursing from proximomedial to a distolateral aspect of the foot was found, representing the lateral plantar vein [1]. There was no blood flow inside the vein, on Doppler imaging (fig 1, video 1, on the journal site). The patient received a diagnosis of lateral plantar vein thrombosis (PVT) and under anticoagulant treatment the foot be-

Received 10.11.2020 Accepted 03.01.2021

Med Ultrason

2021, Vol. 23, No 1, 120-121, DOI: 10.11152/mu-2931,

Corresponding author: Kamal Mezian

Department of Rehabilitation Medicine, First Faculty of Medicine, Charles University and General University Hospital in Prague,

Prague, Czech Republic

E-mail: kamal.mezian@gmail.com

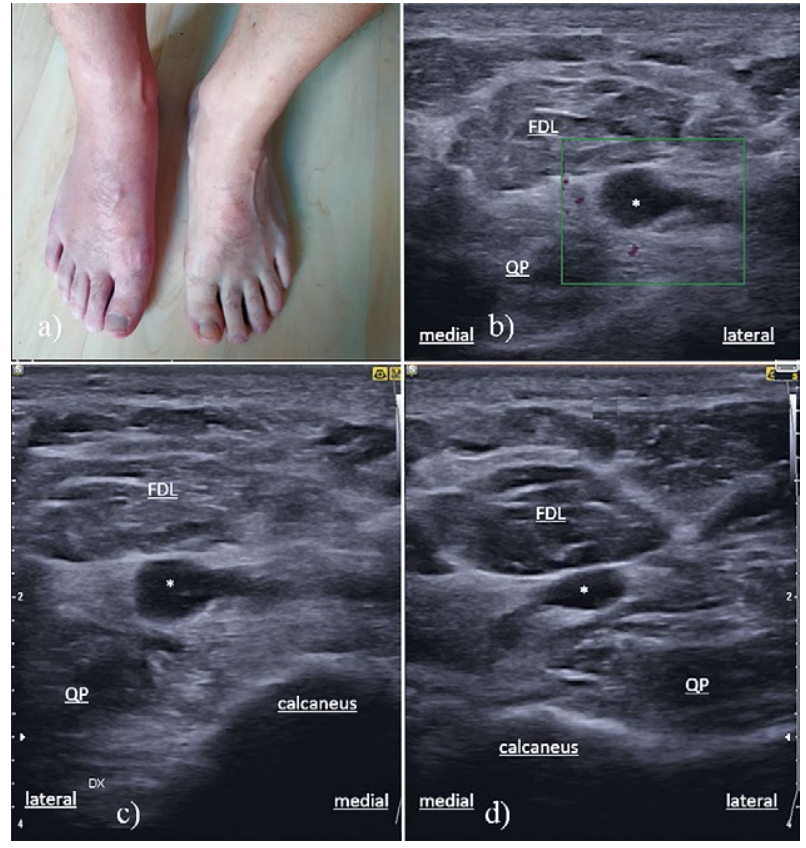

Fig 1. a) A picture shows a swelling and livid skin color of the right foot; b) and c) Axial ultrasound imaging of the plantar aspect of the right foot. The hypoechoic circular non-compressible structure, without blood flow, represents a thrombotic lateral plantar vein (asterisks); d) The easily compressible lateral plantar vein (asterisk) with a flattened shape in the healthy foot. FDL; flexor digitorum longus muscle, QP; quadratus plantae muscle, asterisk; lateral plantar vein

came painless with no functional limitation on the 3rdmonth follow-up.

PVT is not commonly considered as a potential cause of foot pain. Mechanical strain to sole could be a possible risk factor for PVT due to the vessels' repeated microtrauma with consecutive activation of the coagulation cascade. The lateral plantar vein has been reported to be affected most commonly [2]. Fortunately, symptomatic pulmonary embolism is rare in patients with PVT [3]. PVT should be considered an important differential diag- 
nosis of acute foot pain and US examination can readily clarify the clinical scenario.

\section{References}

1. Özçakar L, Kara M, Chang KV, et al. EURO-MUSCULUS/ USPRM. Basic Scanning Protocols for Ankle and foot. Eur J Phys Rehabil Med 2015;51:647-653.
2. Czihal M, Röling J, Rademacher A, Schröttle A, Kuhlencordt P, Hoffmann U. Clinical characteristics and course of plantar vein thrombosis: a series of 22 cases. Phlebology 2015;30:714-718.

3. Barros M, Nascimento I, Barros T, Labropoulos N. Plantar vein thrombosis and pulmonary embolism. Phlebology 2015;30:66-69.

\section{Rare median nerve anatomy - possible cause for carpal tunnel syndrome?}

\section{Michaela Plaikner, Alexander Loizides, Elisabeth Skalla-Oberherber, Hannes Gruber}

\section{Medical University of Innsbruck, Department of Radiology, Innsbruck, Austria}
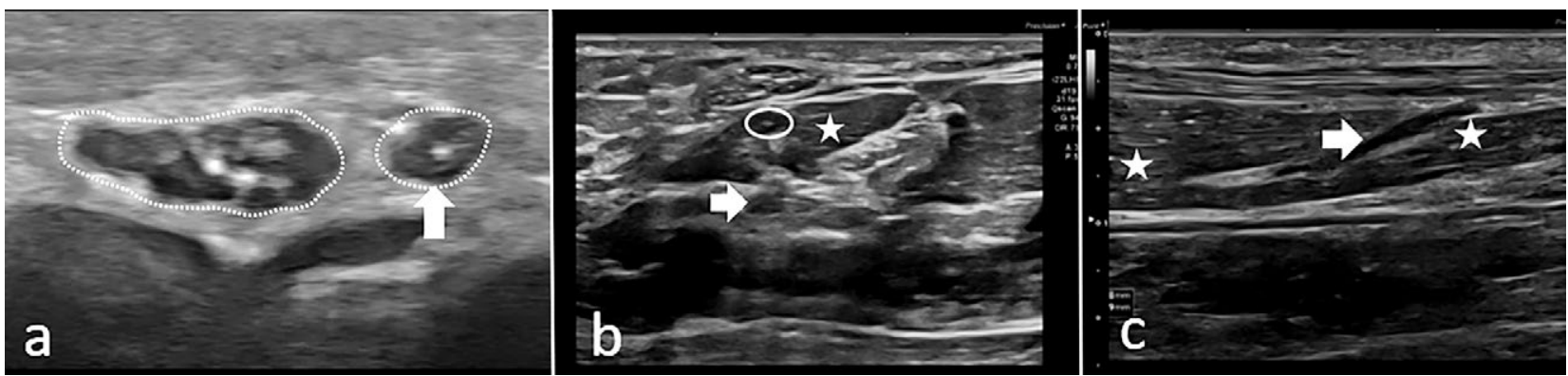

Fig 1. a) Transverse scan of right bifid median nerv (dotted-lines) with its ulnar portion (arrowhead); b) transversal and c) longitudinal scan of the distal right forearm with separated ulnar (circle) median (arrow)-portion running through the superficial flexor digitorum muscle (star).

\section{To the Editor,}

A 43-year-old-woman presented with bilateral hand symptoms with waking-up due to pain and prickling; her swollen, stiff hands recovered during daytime. On the right-hand a recent alarming symptom was present: a "sudden lack-of-force" persisting for minutes when carrying shopping-bags, especially with flexed $3^{\text {rd }}$ and $4^{\text {th }}$ fingers. Electroneurography revealed marginal bilateral

Received 18.11.2020 Accepted 13.12.2020

Med Ultrason

2021, Vol. 23, No 1, 121-122, DOI: 10.11152/mu-2942,

Corresponding author: PD Dr. Alexander Loizides

Medical University of Innsbruck,

Department of Radiology,

35 Anichstraße, 6020, Innsbruck, Austria

E-mail: alexander.loizides@i-med.ac.at

Phone: +43(0)512 50480911

Fax.: +43(0)512 50422758 carpal tunnel syndrome (CTS). High resolution ultrasonography (HRUS) was performed demonstrating an unremarkable bilateral bifid median nerve (MN) with a wrist-forearm-ratio of 1.5 (right-side) and 1.4 (left-side). However, at the right distal forearm the ulnar MN portion- which further distally continued as the third common and radial fourth digital nerve- ran separately "entrapped" transmuscular through the distal part of the superficial flexor digitorum (FDS) muscle (fig 1).

Our special right-sided CTS-constellation with partial transmuscular course did not exactly fall into any of "Lanz nerve anomalies" [1] and could rather be assigned to the Hanna et al proposed "fifth group" that involves otherwise unclassified variations [2]. Kadar et al [3] was the only one to report the existence of this rare median-nerve-variation proposing an additional subgroup named "3D High-division of MN with medial component having a transmuscular course through the FDSmuscle". 
Some authors are convinced that a bifid MN may promote compression; others deny any CTS relation. The described transmuscular course of the "entrapped" portion of the $\mathrm{MN}$ is striking: considering the acute symptoms, this atypical anatomy should be discussed as the underlying, functional nerve compression site, possibly leading to acute ischemia of the trapped nerve portion due to muscle contraction. Similar entrapments are known to be associated with occipital neuralgia and piriformmuscle-syndrome cases. Based on the right-sided actionbased complaints and the special anatomy with partial intramuscular course of the "entrapped" MN-portion an intramuscular botulinum-toxin injection of the concerned FDS might be a possible therapeutic approach. However, the classical transversal carpal ligament dissection seems to have no reasonable therapeutic option.
Without HRUS, this case might have undergone irrelevant tunnel-release with the risk of surgical impairment of a MN-portion without solving the problem. We should be aware of possible coexisting anatomic variants becoming relevant anytime during lifetime in order to provide productive therapeutic options.

\section{References}

1. Lanz U. Anatomical variations of the median nerve in the carpal tunnel. J Hand Surg Am 1977;2:44-53.

2. Hanna AS, Wei Z, Hanna BA. Median Nerve Variation: A Complete Spin before Terminal Branching. J Brachial Plex Peripher Nerve Inj 2020;15:e1-e4.

3. Kadar IA, Virag TH, Matei IR, Georgescu AV. High Division of the Median Nerve with Unusually High Origin of the 3rd Space Common Digital Nerve Injury 2020. doi:10.1016/j.injury.2020.03.024.

\section{Ultrasonography techniques in the preoperative diagnosis of parotid gland tumors - an updated review of the literature}

\section{Georgios Psychogios}

\section{Department of Otorhinolaryngology, University Ioannina, Greece}

\section{To the Editor,}

We read with great interest the manuscript of Stoia et al entitled "Ultrasonography techniques in the preoperative diagnosis of parotid gland tumors - an updated review of the literature" [1]. The authors highlight the importance of preoperative ultrasound (US) in differential diagnosis of parotid tumors and the localization within the parotid gland for better planning of the surgical treatment. We strongly agree with the authors about the importance of preoperative US, but we would like to pay attention to several important missing aspects in the article.

Parotid gland surgery has experienced a great evolution in the last years. Especially the development of extracapsular dissection and partial superficial parotidectomy have contributed to make benign parotid surgery

Received 28.11.2020 Accepted 20.12.2020

Med Ultrason

2021, Vol. 23, No 1, 122-123, DOI: 10.11152/mu-2953,

Corresponding author: Prof. Georgios Psychogios

Department of Otorhinolaryngology,

University Ioannina, Leof. Stavrou Niarchou,

Ioannina 455 00, Greece

E-amil: gpsychogios@uoi.gr less invasive. As shown in a recent review, anatomical criteria such as tumor size, location within the parotid gland and proximity to the facial nerve (FN), are very important in order to choose the best surgical technique [2]. US can greatly assist in localizing parotid tumors within the parotid gland. As the authors correctly describe, assessment of the minimum distance between the parotid fascia and the superficial capsule of the tumor is one possibility to differentiate between superficial and deep parotid lobe tumors. Nevertheless, the best cutoff values are controversial. In a recent study, Mantsopoulos et al found the optimal cutoff value to be $2.6 \mathrm{~mm}$ with diagnostic accuracy less than $90 \%$ [3]. A much more reliable sonographic marker seems to be the proximity of the tumor to the retromandibular vein (RMV). Using the RMV as a landmark, an overall accuracy of tumor localization within the correct lobe could be achieved in $96 \%$ of the patients [4]. Furthermore, the method indirectly predicted if the tumor had contact to the FN and helped surgeons successfully decide which surgical technique was the most appropriate.

The authors point out the value of elastography in differentiating between benign and malignant parotid 
tumors. An important indicator of a malignant parotid tumor is the presence of cervical lymph node metastasis. In a recent prospective study, multimodal US with VTIQ Elastography could be shown to greatly assist identification of malignant lymph nodes that are an important indicator of malignant parotid tumors [5].

Finally, we would like to point out two inaccuracies of the article. The estimated prevalence of Warthin's tumors is much higher that $15-30 \%$. Recent literature has shown that the prevalence of Warthin's tumors has increased in recent years and in some cases is the most common benign parotid gland tumor [6]. In fig 1 the authors mistakenly talk about necrotic areas. Warthin's tumors do not have necrotic but cystic areas.

\section{References}

1. Stoia S, Baciut G, Lenghel M, et al. Ultrasonography techniques in the preoperative diagnosis of parotid gland tumors - an updated review of the literature. Med Ultrason 2020, DOI: $10.11152 / \mathrm{mu}-2652$.
2. Psychogios G, Bohr C, Constantinidis J, et al. Review of surgical techniques and guide for decision making in the treatment of benign parotid tumors. Eur Arch Otorhinolaryngol, 2020, DOI: 10.1007/s00405-020-06250-x.

3. Mantsopoulos K, Tschaikowsky N, Goncalves M, Mueller SK, Iro H Evaluation of preoperative Ultrasonography in the Differentiation between Superficial and Deep Parotid Gland Tumors. Ultrasound Med Biol 2020;46:20992103.

4. Psychogios G, Rueger H, Jering M, Tsoures E, Kunzel J, Zenk J. Ultrasound can help to indirectly predict contact of parotid tumors to the facial nerve, correct intraglandular localization, and appropriate surgical technique. Head Neck 2019;41:3211-3218.

5. Ruger H. Psychogios G, Jering M, Zenk M. Multimodal Ultrasound Including Virtual Touch Imaging Quantification for Differentiating Cervical Lymph Nodes. Ultrasound Med Biol 2020;46:2677-2682.

6. Psychogios G, Vlastos I, Thölken R, Zenk J. Warthin's tumour seems to be the most common benign neoplasm of the parotid gland in Germany. Eur Arch Otorhinolaryngol 2020;277:2081-2084.

\section{Author's response}

\section{Sebastian Stoia ${ }^{1}$, Grigore Băciuț ${ }^{1}$, Manuela Lenghel ${ }^{2}$, Radu Badea $^{3}$, Mihaela Băciuț ${ }^{1}$, Simion Bran $^{1}$, Cristian Dinu ${ }^{1}$}

${ }^{1}$ Department of Maxillofacial Surgery and Implantology, ${ }^{2}$ Department of Radiology, ${ }^{3}$ Department of Medical Imaging „Prof. Dr. Octavian Fodor” Regional Institute of Gastroenterology, "Iuliu Haţieganu” University of Medicine and Pharmacy, Cluj-Napoca, Romania

\section{Dear Editor,}

We appreciate Prof. Georgios Psychogios's interest in our review and we have read with interest his comments.

The distance less than $2.4 \mathrm{~mm}$ between the parotid fascia and the parotid tumor correlates with the tumor localization in the superficial lobe [2]. Cheng et al indicated a cutoff value of $2.4 \mathrm{~mm}$ very close to the value of 2.6 of the Mantsopoulos et al study, which was not published when we submitted our article for publication $[2,3]$.

The retromandibular vein is an important landmark for parotid tumors localization, but we consider that the use of this landmark in predicting the relationship of parotid tumor to the facial nerve by US still has some limitations: MRI techniques provide superior results [4]. We showed that VTIQ elastography can provide additional data in distinguishing benign from malignant parotid tumors $[5,6]$.
Recent studies have shown an increased incidence of Warthin tumors, but their results are difficult to generalize because these studies were performed on patients from certain geographical regions $[7,8]$. Tunç et al showed that pleomorphic adenoma still occupies the first place among benign parotid tumors. No significant annual percentage change of the Warthin tumor incidence was observed according to the segmented regression analysis [8].

Rarely the Warthin tumors present areas of squamous metaplasia. In this case Warthin tumors can be accompanied by tumor necrosis $[9,10]$.

\section{References}

1. Stoia S, Baciut G, Lenghel M, et al. Ultrasonography techniques in the preoperative diagnosis of parotid gland tumors - an updated review of the literature. Med Ultrason 2020 Oct 14. doi:10.11152/mu-2652.

2. Cheng PC, Chang CM, Huang CC, et al. The diagnostic performance of ultrasonography and computerized tomog- 
raphy in differentiating superficial from deep lobe parotid tumours. Clin Otolaryngol 2019;44:286-292.

3. Mantsopoulos K, Tschaikowsky N, Goncalves M, Mueller SK, Iro H. Evaluation of preoperative Ultrasonography in the Differentiation between Superficial and Deep Parotid Gland Tumors. Ultrasound Med Biol 2020;46:2099-2103.

4. Attyé A, Karkas A, Troprès I, et al. Parotid gland tumours: MR tractography to assess contact with the facial nerve. Eur Radiol 2016;26:2233-2241.

5. Zengel P, Notter F, Reichel CA, Clevert DA. Does Virtual Touch IQ elastography help to improve the preoperative diagnosis of parotid tumors: A prospective trial. Clin Hemorheol Microcirc 2017;67:425-434.

6. Zengel P, Notter F, Clevert DA. Does acoustic radiation force elastography improve the diagnostic capability of ultrasound in the preoperative characterization of masses of the parotid gland? Dentomaxillofac Radiol 2018;47:20180068.

7. Psychogios G, Vlastos I, Thölken R, Zenk J. Warthin's tumour seems to be the most common benign neoplasm of the parotid gland in Germany. Eur Arch Otorhinolaryngol 2020;277:2081-2084.

8. Tunç O, Gönüldaş B, Arslanhan Y, Kanlıkama M. Change in Warthin's tumor incidence: a 20-year joinpoint trend analysis. Eur Arch Otorhinolaryngol 2020;277:3431-3434.

9. Yorita K, Nakagawa H, Miyazaki K, Fukuda J, Ito S, Kosai M. Infarcted Warthin tumor with mucoepidermoid carcinoma-like metaplasia: a case report and review of the literature. J Med Case Rep 2019;13:12.

10. Kato H, Kanematsu M, Mizuta K, Aoki M, Hirose Y. Spontaneous infarction of Warthin's tumor: imaging findings simulating malignancy. Jpn J Radiol 2012;30:354-357.

\section{Advances in the application of Doppler ultrasonography in the newborn}

\section{Peter Anto Johnson ${ }^{1}$, John Christy Johnson ${ }^{2}$}

${ }^{1}$ Department of Medicine, ${ }^{2}$ Department of Biomedical Engineering, Faculty of Medicine \& Dentistry, University of Alberta, Edmonton, Canada

\section{To the Editor,}

Over the past five years, Doppler ultrasound (DUS) has gained traction for its utility in neonatal monitoring, diagnostics and prognostics (Table I).

Heart rate monitoring in the delivery room has been explored with an exponential interest in the application of DUS for assessment at birth and/or during neonatal resuscitation [1]. Compared to existing recommendations, DUS offers an accurate and rapid assessment, significant for neonatal resuscitation where these assessments guide critical interventions. However, the accuracy and reliability are limited by operator technique and signal interference due to gasping in asphyxia or hypoxia and/ or movement artefacts.

Received 07.01.2021 Accepted 25.01.2021

Med Ultrason

2021, Vol. 23, No 1, 124-125, DOI: 10.11152/mu-3018,

Corresponding author: Peter Anto Johnson

116 St \& 85 Ave NW, Edmonton AB, Canada

Phone: $780-485-2430$

Fax: 780-485-2430

E-mail: paj1@ualberta.ca
DUS also has significance in early diagnosis of neonatal ischemic stroke (NIS). This is especially salient as MRI, which is the diagnostic standard of choice, is not always readily accessible. High-resolution duplex ultrasound can detect ischemic strokes and DUS can differentiate complete occlusion from severe stenosis safely and non-invasively. Moreover, DUS guides therapeutic measures on the basis of recanalization of vessels and visualization of cyst formation from liquefactive necrosis. Nevertheless, operator technique and inaccuracies may result from poor acoustic window (i.e., skull, soft tissues, etc.)

Another practical application of DUS is in early diagnosis and outcome prediction in cases of HIE. Similar to NIS diagnosis, 2D duplex and DUS can be combined to examine cerebral parenchyma, size of lateral ventricles and hemodynamic parameters of cerebral arteries. Abnormal findings including cystic parenchymal lesions, progressive ventricular dilatation and brain atrophy, mild ventricular dilatation, and leukoencephalomalacia are relevant for early HIE diagnosis and prognosis. Despite its promise, we anticipate similar limitations that were observed in NIS diagnosis. 
Table I. Novel utilities of Doppler ultrasonography techniques in the newborn. This table represents five applications that have advanced in the recent decade summarizing their strengths and limitations for clinical implementation.

\begin{tabular}{|c|c|c|c|}
\hline Application & Technique(s) & Strengths & Limitations \\
\hline $\begin{array}{l}\text { Heart rate } \\
\text { assessment } \\
\text { at birth / } \\
\text { during NR }\end{array}$ & DUS & $\begin{array}{l}\text { Non-invasive and safe } \\
\text { Fast and accurate heart rate guides } \\
\text { critical interventions } \\
\text { at birth and during NR } \\
\text { Can be used for monitoring or } \\
\text { intermittent assessment }\end{array}$ & $\begin{array}{l}\text { Operator-dependent inaccuracies } \\
\text { (e.g., improper technique, excessive movement, } \\
\text { errors in signal interpretation, etc.) } \\
\text { Signal interference from gasping, ventilator, } \\
\text { and movement } \\
\text { Low perfusion conditions (i.e., bradycardia) can affect } \\
\text { signal quality }\end{array}$ \\
\hline $\begin{array}{l}\text { Diagnosis of } \\
\text { NIS }\end{array}$ & $\begin{array}{l}\text { DUS + } \\
\text { Hi-res } \\
\text { duplex } \\
\text { ultrasound }\end{array}$ & $\begin{array}{l}\text { Non-invasive and safe } \\
\text { Detects NIS with high accuracy } \\
\text { Differentiates complete occlusion } \\
\text { from severe stenosis } \\
\text { Can be used to guide therapeutic } \\
\text { interventions }\end{array}$ & $\begin{array}{l}\text { Operator-dependent inaccuracies } \\
\text { Lower resolution and harder to interpret, relative to MRI } \\
\text { Poor acoustic window (i.e., skull, soft tissue, etc.) }\end{array}$ \\
\hline $\begin{array}{l}\text { Diagnosis \& } \\
\text { prognosis of } \\
\text { HIE }\end{array}$ & $\begin{array}{l}\text { DUS + } \\
2 \mathrm{D} \\
\text { duplex } \\
\text { ultrasound }\end{array}$ & $\begin{array}{l}\text { Non-invasive and safe } \\
\text { Visualization of cerebral parenchyma, } \\
\text { lateral ventricles, arteries, etc. } \\
\text { Detection of hemodynamic parameters } \\
\text { Prognostic and diagnostic value }\end{array}$ & $\begin{array}{l}\text { Operator-dependent inaccuracies } \\
\text { Poor acoustic window (i.e., skull, soft tissue, etc.) }\end{array}$ \\
\hline $\begin{array}{l}\text { Neonatal } \\
\text { brain } \\
\text { imaging }\end{array}$ & $\begin{array}{l}\text { Ultrafast } \\
\text { DUS }\end{array}$ & $\begin{array}{l}\text { Non-invasive and safe } \\
\text { Comparable accuracy to conventional } \\
\text { DUS } \\
\text { Improved acquisition time } \\
\text { Enhanced distal cranial artery evaluation } \\
\text { Quantitative data can be acquired }\end{array}$ & $\begin{array}{l}\text { Operator-dependent inaccuracies } \\
\text { Poor acoustic window (i.e., skull, soft tissue, etc.) } \\
\text { Hardware and image quality limitations }\end{array}$ \\
\hline $\begin{array}{l}\text { Prognosis } \\
\text { of NEC } \\
\text { in sepsis }\end{array}$ & DUS & $\begin{array}{l}\text { Non-invasive and safe } \\
\text { Predictor of NEC for at-risk septic } \\
\text { preterm infants }\end{array}$ & $\begin{array}{l}\text { Operator-dependent inaccuracies } \\
\text { Low sample size evidence } \\
\text { Low perfusion conditions could affect signal quality }\end{array}$ \\
\hline
\end{tabular}

NR, neonatal resuscitation; NIS, neonatal ischemic stroke; HIE, hypoxic-ischemic encephalopathy; NEC, necrotizing enterocolitis; DUS, Doppler ultrasound

A state-of-the-art development in DUS technology has been Ultrafast DUS, which has shown potential for enhancing neonatal cranial ultrasound and brain imaging for cranial ultrasound in neonates [2]. We measured the peak systolic velocity (PSV. Not only have advances enabled detection of peak systolic velocity (PSV), end-diastolic velocity (EDV) and resistive index of the cerebral arteries with comparable accuracy to conventional DUS, shorter acquisition times have been demonstrated. Furthermore, quantitative information can be collected and distal cranial artery evaluation is enhanced using Ultrafat DUS.

Although in its early advances, DUS could also be utilized as a prognostic tool for septic preterm infants at risk for NEC. In a recent study, significantly low PSV and EDV in the superior mesenteric artery and higher celiac PSV to superior mesenteric PSV ratio was determined in septic preterms that developed NEC [3]. Though limited in sample size and perhaps flow velocimetry signal interference in low perfusion septic infants, we believe this application may become clinically practical.

\section{References}

1. Johnson PA, Cheung P-Y, Lee T-F, O’Reilly M, Schmölzer GM. Novel technologies for heart rate assessment during neonatal resuscitation at birth - A systematic review. Resuscitation 2019;143:196-207.

2. Kim HG, Lee JH. Feasibility of Ultrafast Doppler technique for cranial ultrasound in neonates. Med Ultrason 2019;21:288-293.

3. Hashem RH, Mansi YA, Almasah NS, Abdelghaffar S. Doppler ultrasound assessment of the splanchnic circulation in preterms with neonatal sepsis at risk for necrotizing enterocolitis. J Ultrasound 2017;20:59-67. 